\title{
Understanding Beach Health Throughout the Great Lakes- Continuing Research
}

The overall mission of U.S. Geological Survey (USGS) Beach Health Initiative is to provide science-based information and methods that will allow beach managers to more accurately make beach closure and advisory decisions, understand the sources and physical processes affecting beach contaminants, and understand how science-based information can be used to mitigate and restore beaches and protect the public.

The USGS, in collaboration with many Federal, State, and local agencies and universities, has conducted research on beach-health issues in the Great Lakes Region for more than a decade. The work consists of four science elements that align with the initiative's mission: real-time assessments of water quality; coastal processes; pathogens and source tracking; and data analysis, interpretation, and communication. The ongoing or completed research for each of these elements is described in this fact sheet.

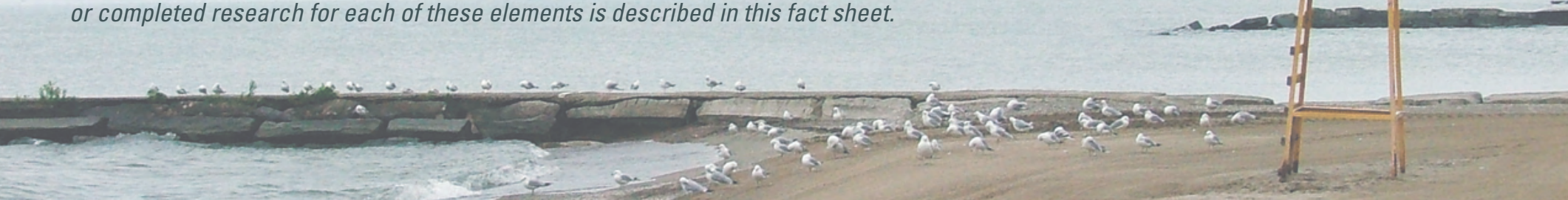

\section{Background}

Proper stewardship of our Nation's coastal areas, including the Great Lakes region, must be shared by numerous government agencies, academia, and other stakeholders so that the public can use and enjoy the natural resources that coastal areas provide. In 2000, Congress established the U.S. Commission on Ocean Policy and tasked this group to investigate and provide recommendations for a "coordinated and comprehensive national ocean policy"; the result was the Ocean Research Priorities Plan (ORPP) and Implementation Strategy. The ORPP defines research priorities that focus on understanding critical coastal processes and interactions and applying that understanding toward stewardship and responsible use of the oceans and the Great Lakes. In 2009, furthering this national strategy, President Obama introduced the Great Lakes Restoration Initiative (GLRI), whose Action Plan identifies goals, objectives, measurable ecological targets, and specific actions for each of five focus areas: (1) toxic substances and areas of concern, (2) invasive species, (3) nearshore health and nonpoint source pollution, (4) habitat and wildlife protection and restoration, and (5) accountability, education, monitoring, evaluation, communication and partnerships. The ORPP and GLRI Action Plan are heavily influenced by stakeholders identifying specific scientific needs for the Nation's coastal areas. As such, these programs are designed to build a community of local, State, and Federal agencies and entities working together to reach common goals without duplicating research efforts.

\section{The "Beach Health" Issue, and Why It Is Important}

Beaches across the Nation face multiple challenges that affect water quality, including erosion, contamination from pathogens (disease-causing organisms), and eutrophication. Advisories and closings are intended to protect the public from coming into contact with pathogens; however, several problems face beach managers who issue advisories or closures or try to solve contamination problems:

- Traditional laboratory analyses for determining beach water quality take too long. Fecal-indicator bacteria (FIB), such as E. coli and enterococci, are currently used in beach water-quality monitoring to determine whether to post an advisory or closing. Although not necessarily pathogenic themselves, FIB indicate the possible presence of pathogens. Current laboratory analyses for FIB can take up to 18 hours to obtain results; consequently, beach postings or closures are based on outdated results.

- Recreational waters are seldom monitored for actual pathogens. FIB are used to indicate the possible presence of pathogens but may not have the same survival properties as all pathogens. For example, FIB in the environment may not survive as long as pathogens, falsely indicating safety; conversely, FIB may survive or grow longer than pathogens, falsely indicating risk. Laboratory methods for pathogens tend to be expensive and pathogen specific. It would be cost prohibitive and time consuming to analyze for a large suite of pathogens routinely; and even if such analyses were feasible, a nondetection may not indicate the absence of pathogens, only that those in the analysis suite were not found.

- Sources of fecal contamination in recreational waters are often unknown. Physical and biological processes at beaches can influence the occurrence and abundance of FIB and pathogens; however, the relations between these processes and FIB or pathogen concentrations are not well understood. Also, laboratory methods to distinguish between prevalent sources of fecal contamination, which could greatly aid with restoration efforts, are not routinely used because of the potential ambiguity of results without corroborating findings from intensive studies of the physical processes affecting the watershed.

- Data used in the study of recreational waters are sometimes inconsistent between beaches. Currently, data are compiled by numerous agencies in a variety of formats, and these inconsistent formats can create difficulties for scientists to make comparisons across beaches and regions. 


\section{Real-Time Assessments of Water Quality}

Water quality can change rapidly at beaches in response to varying meteorological conditions and other factors such as currents, waves, and seiches; combined-sewer overflows; and even the numbers of birds and visitors at the beach. Predictive modeling has been explored as a tool for quickly assessing water quality to make management decisions on beach advisories or closures. The USGS and collaborators have been investigating predictive modeling for more than a decade.

Currently (2012), statistical modeling is being used or tested for use in predicting real-time water-quality conditions at 48 coastal beaches across the Great Lakes region. Daily beach sanitary surveys and samples collected by technicians and state-of-the-art equipment deployed at or near beaches are being used to assist in understanding the relations between environmental and meteorological factors and FIB concentrations. The models, referred to as "nowcasts," use these relations to make predictions of current water-quality conditions at the beach. As of 2012, there are four Lake Erie and four Lake Michigan beaches with operational nowcasts in the USGS study. Operational nowcasts are used for 4 to 7 days per week during the recreational season (May-September), and the model results are posted at the beach and (or) online to inform the public of current water-quality conditions at each beach (www.ohionowcast.info; www.wibeaches.us; www.cfmstage.com). Forty more nowcasts were being tested during 2012 to determine whether to make them operational in 2013 or 2014.

Other related USGS involvement includes testing of rapid analytical methods to determine FIB concentrations in water and testing of alternative statistical techniques to improve the accuracy of model predictions. The USGS plans to continue working with collaborators to assist with developing and expanding current nowcasts by providing technical assistance and training; for example, the USGS is hosting workshops on the use of model-development tools such as Virtual Beach, a software package designed for developing site-specific predictive models (U.S. Environmental Protection Agency, 2012), and PROCESSNOAA and other USGS-developed tools for synthesizing large amounts of data (see box below). The USGS has implemented various modern statistical techniques for development of predictive models that broaden the modeling options available. Future releases of the Virtual Beach software are planned to include some options. Continued collaboration with U.S. Environmental Protection Agency (USEPA) to advance the functional and technical capabilities of VB is also planned.

For further information regarding USGS nowcasts, contact Donna Francy (dsfrancy@usgs.gov).

\section{What is a Nowcast?}

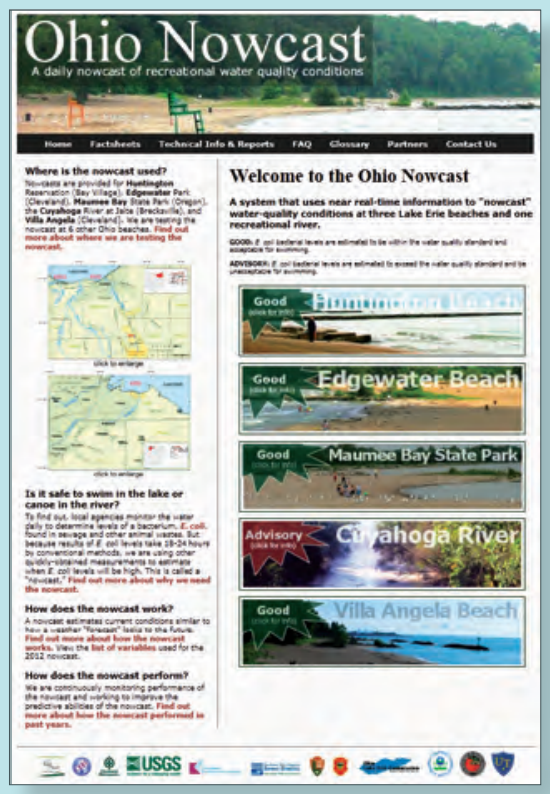

A nowcast estimates current conditions similar to the way a weather forecast looks to the future. Nowcasts predict whether a specific site on a beach or river will exceed the water-quality standard on a given day. Mathematical models that use easily measured environmental and (or) water-quality variables, such as turbidity and rainfall, are used to estimate concentrations of fecal indicator bacteria. Because of different topographical and meteorological influences that affect beaches across the Great Lakes region, nowcasts are typically site specific.

\section{USGS training and tools for predictive modeling}

In December 2011 at the Ohio Water Science Center in Columbus, Ohio, the USGS hosted a predictive modeling workshop. More than 30 participants from local and State agencies and USGS offices across the Great Lakes region attended the workshop. Participants were guided through the process for developing predictive models, using data from their local beaches. Instructors from the USGS, USEPA, and Wisconsin Department of Natural Resources provided the hands-on training, which included an introduction to PROCESSNOAA, a Graphical User Interface (GUI) that assists in processing large quantities of climatological data provided by National Oceanic and Atmospheric Administration (NOAA). Hourly precipitation totals and predominant wind speed and direction data are routinely collected at airports across the country. These data are often used in predictive modeling at beaches but could require hours for the modeler to synthesize manually. PROCESSNOAA synthesizes the hourly data and saves these data in a format ready for direct import into Virtual Beach. PROCESSNOAA also features interactive time-series plots of rainfall and wind speed and direction, as well as a compass plot of the daily wind speed and direction vectors.

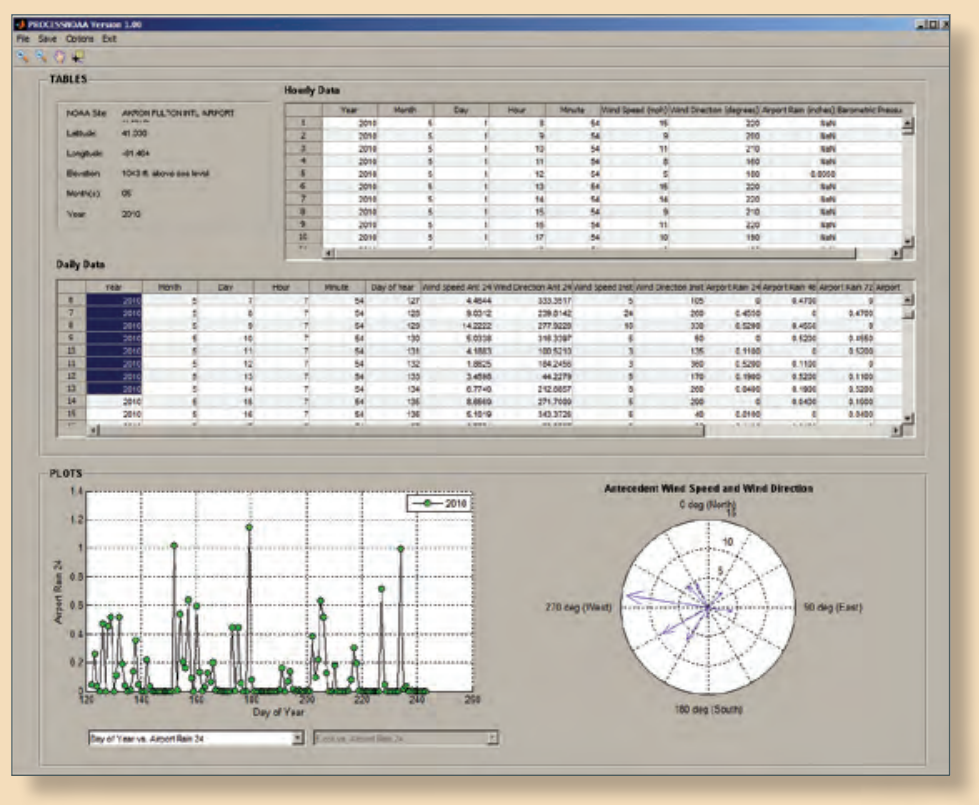

PROCESSNOAA screenshot. 


\section{Coastal Processes Research}

Processes such as sediment transport, turbulence associated with currents and wave action, changes in lake and groundwater levels, surfacewater inputs, and seiches can all have an effect on bacteria concentrations. Further, beach sands and algae (such as Cladophora) can accumulate and harbor FIB and pathogens that can later be reintroduced into lake water. USGS scientists are working to characterize the transfer of FIB and pathogens to nearshore waters by way of these processes. In a series of studies examining the interaction between water movement and bacteria concentrations, several contributing processes have been identified:

- Wave height and FIB resuspension from beach sands: USGS scientists calculated lakebed shear stress and wave runup to describe the mobilizing mechanism of bacteria from sand to water. Resuspension is particularly important at embayed beaches, where beach sand tends to concentrate E. coli. Further studies are examining the fate of these resuspended bacteria in both embayments and along coastlines.

- Diurnal pattern of FIB (decrease through daylight hours and rebound after dark): USGS scientists determined that some of this nightly increase could be attributed to wave-induced mass transport; that is, the movement of indicator bacteria from intermediate depths to shallow depths during the night. The combination of this transport and nearshore sand resuspension effectively accounts for the increase in FIB concentrations.

- Embayments as FIB "traps": USGS scientists determined that offshore sources of bacteria that enter into the embayment are trapped because of enclosed circulation patterns, leading to increased concentrations of bacteria in the beach area. This finding is particularly important because it may help explain incidents of high bacteria concentrations at beaches without a significant point source of contamination.

The findings from these studies will help establish factors that influence fluctuations in microorganism concentrations and highlight potential approaches for beach restoration.

For further information regarding USGS studies of coastal processes, contact Meredith Nevers (mnevers@usgs.gov).

\section{Pathogens and Source Tracking}

FIB are used to indicate the possible presence of pathogens, but there is little comprehensive information available about the types of pathogens present at Great Lakes beaches and their relations to FIB concentrations. Sampling for pathogens can be challenging, time-consuming, and expensive, and the best methods to simultaneously filter and concentrate all classes of pathogens (bacteria, viruses, and protozoa) from the required large volumes of lake water have not been comprehensively tested. Further, tracking sources of microbial inputs is important for understanding where and how to mitigate contamination to beaches, but there have been few assessments of microbial source-tracking markers at these beaches. USGS scientists have recently been addressing all these data gaps:

- USGS scientists are finalizing results of a study involving 12 Great Lakes beaches where more than 350 samples were collected and analyzed for genetic markers from 5 bacterial pathogens. Pathogen gene detections are being evaluated with respect to both $E$. coli- and enterococci-based recreational water-quality criteria, as well as with regard to a variety of environmental conditions and geographic variables that may influence pathogen occurrence. Preliminary results indicate that bacterial pathogens were not uniformly distributed among the 12 beaches, with some beaches having greater detection frequencies of one pathogen as opposed to others.

- Of the above-mentioned 350 beach samples, 145 were also analyzed for three genes that indicate potential fecal sources: human, ruminant, and gull. At least two sources were detected at each beach, further emphasizing the complexity of beach indicator-bacteria and pathogen dynamics.

- USGS scientists completed a laboratory study to test and evaluate six filtration methods for recovery and variability of bacteria, viruses, and protozoa in 10-liter tapwater and lake-water samples. Preliminary findings indicate that use of an ultrafiltration method resulted in highest recoveries and lowest variability among all microorganisms analyzed for. Two of the filtration methods were successfully scaled up to deployment in the field, where a 200-liter sample of water was processed.

For further information regarding USGS pathogens and source-tracking studies, contact Sheridan Haack (skhaack@usgs.gov).

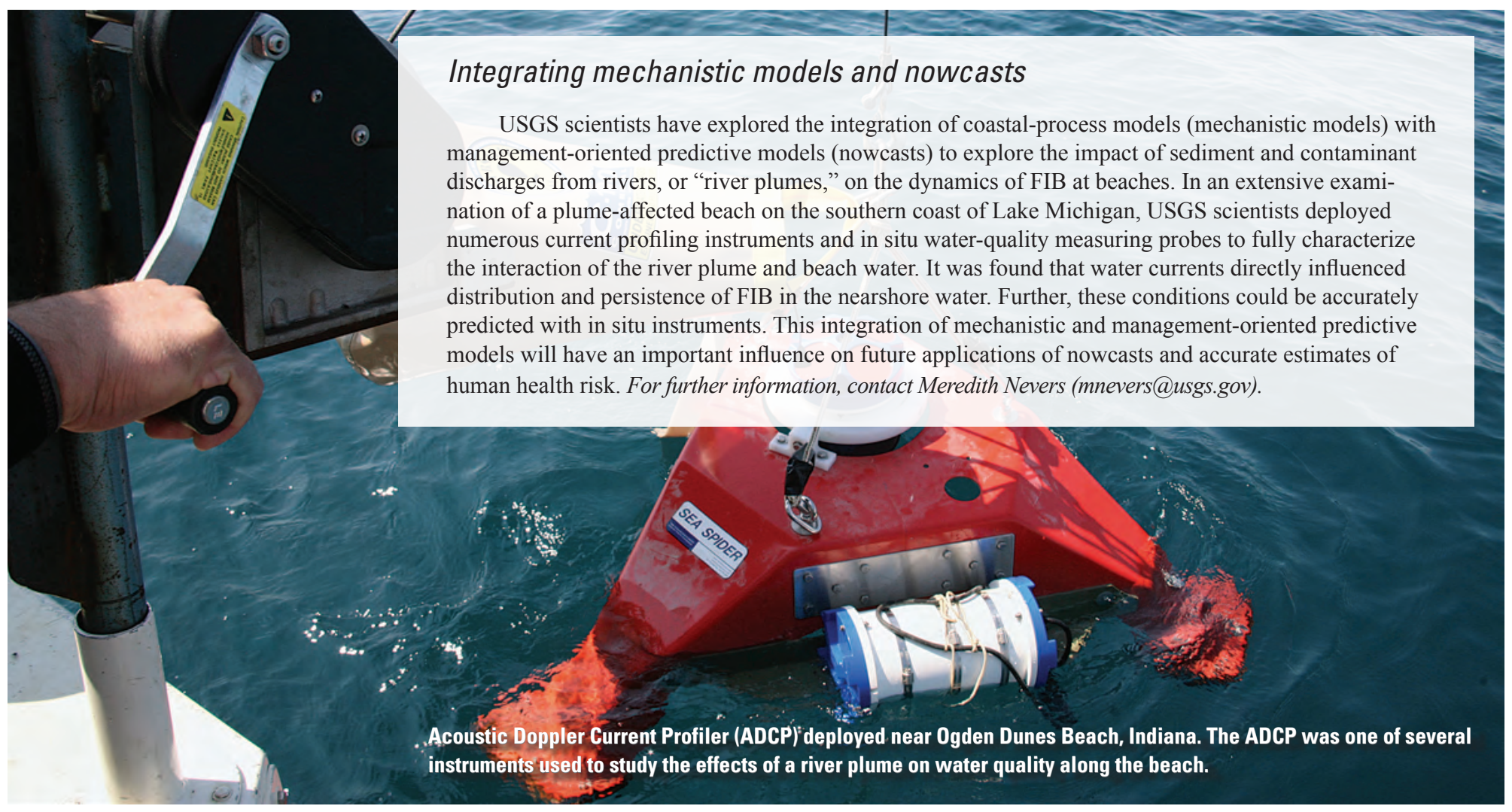




\section{Field testing of a pathogen sampler}

At a subset of three Lake Michigan beaches, water was sampled by using large-volume glass wool filtration for analysis of 22 waterborne pathogens. These three beaches were chosen to represent a range of land uses in the surrounding watershed (rural, agricultural, and urban). A total of 71 samples were collected during the summer of 2010 at these three beaches. Preliminary analysis indicates a very high detection frequency of human viruses and pathogenic bacteria, no detection of protozoa, and lower detection and concentration of bovine viruses than of human viruses. Human and bovine viruses and pathogenic bacteria were detected at all three beaches, indicating the influence of multiple sources at these beaches. Pathogen results are being examined along with water-quality and environmental data from water samples collected concurrently with the pathogen samples (turbidity, water temperature, wave height, and various other parameters). In addition, data retrieved from USGS, NOAA, and the National Weather Service through the Environmental Data Discovery and Transformation (EnDDaT) system (described below) are being used to develop statistical models and to determine which variables best explain variability and magnitude of pathogen occurrence.

For further information, contact Steve Corsi (srcorsi@usgs.gov).

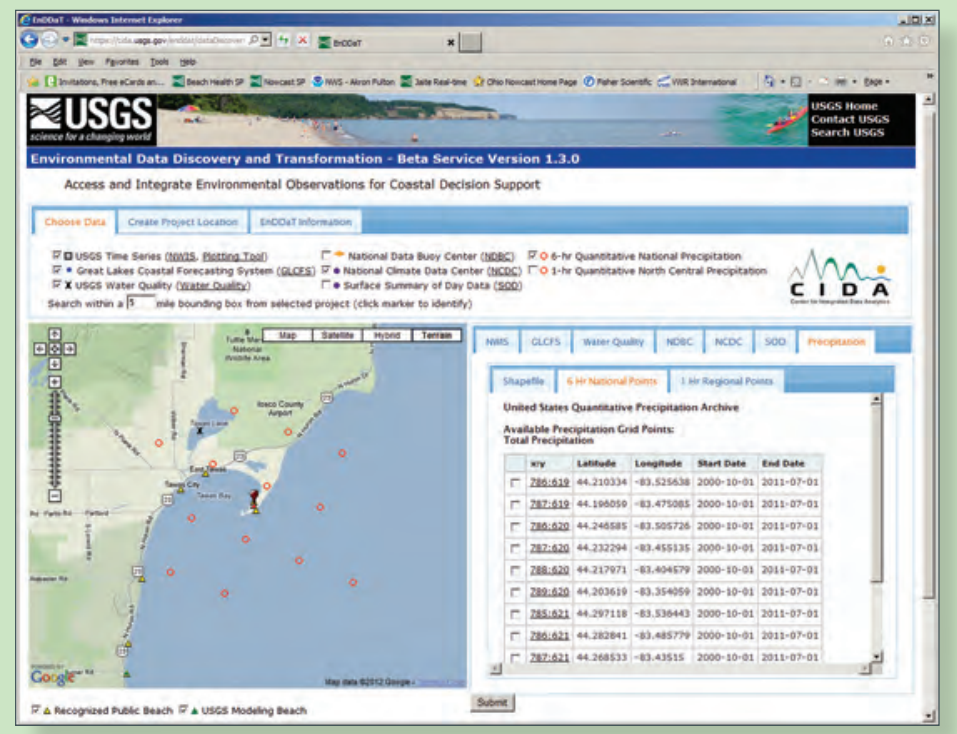

EnDDaT screenshot.

\section{Data Analysis, Interpretation, and Communication}

Data used in the study of recreational waters are sometimes inconsistent because environmental and water-quality data currently are compiled by numerous agencies in a variety of formats. As a result, data discovery, aggregation, and processing can be inefficient and a barrier to environmental data analysis and modeling. USGS scientists have worked closely with partner organizations to develop tools that will be of the most help in compiling and organizing these data to allow for an easy transition to visualization and predictive modeling software.

- A Great Lakes Beach Health Database was created to allow for use across States and agencies. A Web application was created to allow for easy data input into the database. The system currently holds more than 4,400 sanitary survey records from Great Lakes beaches in Wisconsin, New York, Michigan and Ohio. Users are able to view records, edit records, and perform custom exports from the system by filtering data on the basis of date, form type (beach, monitoring point, or tributary), and data parameter group and by choosing the file format to be exported.
- The EnDDaT tool was created to aid in data analysis, model development, and model implementation by allowing scientists to efficiently obtain, aggregate, and manipulate the data necessary for these purposes. This tool was developed with the capabilities of retrieving publicly available data resources through standard Web services, aggregating the disparate data sources, and processing the data through a single Web-accessible user interface (https://cida.usgs.gov/ enddat/). In addition, the tool features a variety of output formats and data visualization tools.

- These tools were created to work together to allow for processed data from EnDDaT to work in conjunction with monitoring data from the Great Lakes Beach Health Database to run nowcasts in real time. Upon execution of the predictive model (developed using Virtual Beach), model input and results are also archived in the database.

For further information on USGS studies regarding beach data analysis, interpretation, and communication, contact Steve Corsi (srcorsi@usgs.gov).

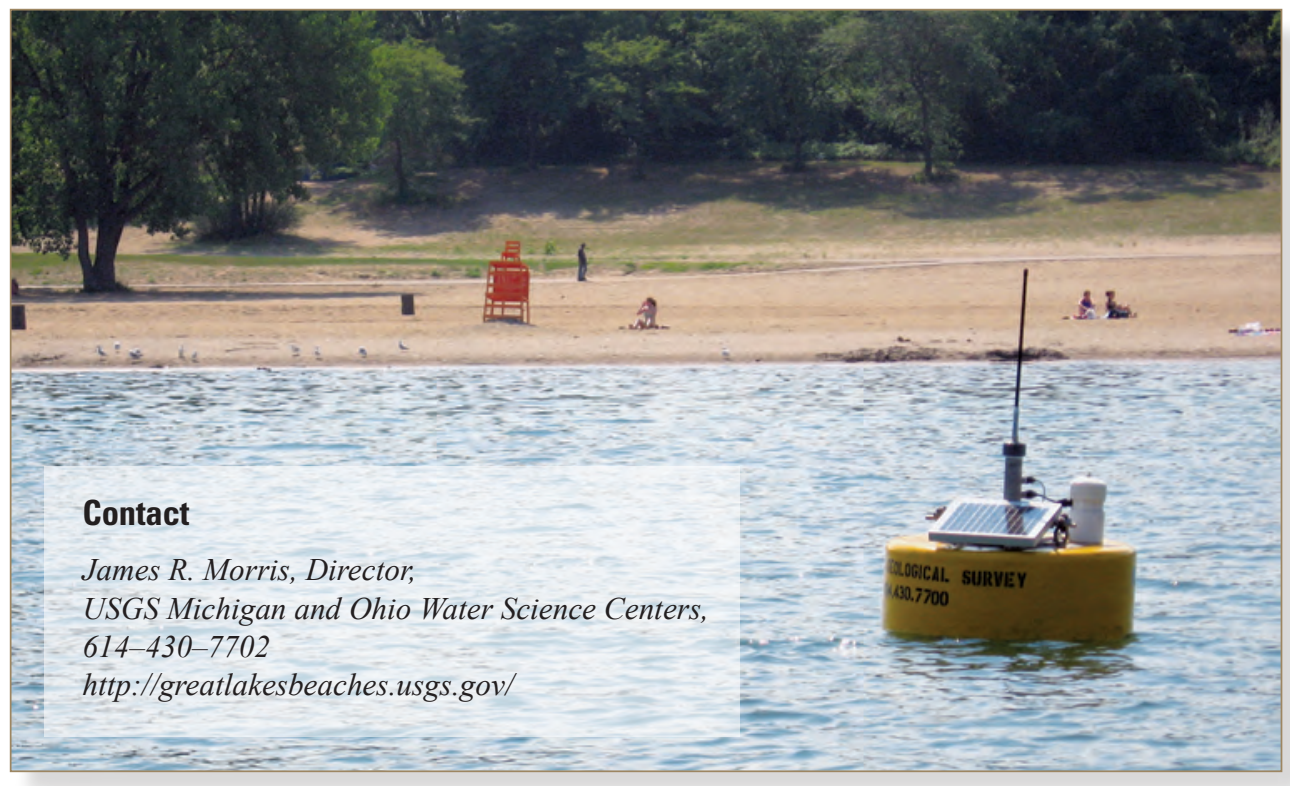

\section{References}

U.S. Environmental Protection Agency, 2012, Exposure Assessment ModelsVirtual Beach, accessed June 11, 2012, at http://www.epa.gov/ceampubl/swater/vb2/.

\section{Program Information}

Funding for USGS beach projects and research in the Great Lakes comes from a variety of sources including the Ocean Research Priority Plan, the USGS, the Great Lakes Restoration Initiative, the U.S. Environmental Protection Agency, and many State and local partner agencies and organizations throughout the region. 